\title{
BMJ Open Effect of ambient air pollution on the incidence of colorectal cancer among a diabetic population: a nationwide nested case-control study in Taiwan
}

\author{
Jen-Wen Ma (D) , ${ }^{1,2}$ Ting-Ju Lai, ${ }^{3}$ Sung-Yuan Hu, ${ }^{1,2}$ Tzu-Chieh Lin, ${ }^{1}$ Wen-Chao Ho, ${ }^{3}$ \\ Yu-Tse Tsan (1) 1,2,4
}

To cite: Ma J-W, Lai T-J, Hu S-Y, et al. Effect of ambient air pollution on the incidence of colorectal cancer among a diabetic population: a nationwide nested case-control study in Taiwan. BMJ Open 2020;10:e036955. doi:10.1136/ bmjopen-2020-036955

- Prepublication history for this paper is available online. To view these files, please visit the journal online (http://dx.doi org/10.1136/bmjopen-2020036955).

Received 30 January 2020 Revised 08 August 2020 Accepted 13 August 2020

Check for updates

(c) Author(s) (or their employer(s)) 2020. Re-use permitted under CC BY-NC. No commercial re-use. See rights and permissions. Published by BMJ.

${ }^{1}$ Department of Emergency Medicine, Taichung Veterans General Hospital, Taichung, Taiwan

${ }^{2}$ School of Medicine, Chung

Shan Medical University,

Taichung, Taiwan

${ }^{3}$ Department of Public Health, China Medical University,

Taichung, Taiwan

${ }^{4}$ Division of Occupational Medicine, Department of Emergency Medicine, Taichung Veterans General Hospital, Taichung, Taiwan

Correspondence to Dr Yu-Tse Tsan; janyuhjer@gmail.com and Dr Wen-Chao Ho; whocmu@gmail.com

\section{ABSTRACT}

Objectives An increasing number of studies had shown that air pollution exposure may aggravate blood glucose control in patients with diabetes, an independent risk factor for colorectal cancer (CRC) proposed by some researchers. This study aimed to investigate the impact of exposure to ambient particulate matter with aerodynamic diameters $\leq 2.5 \mu \mathrm{m}\left(\mathrm{PM}_{25}\right)$ on the incidence of $\mathrm{CRC}$ among a diabetic population.

Design A nested case-control study.

Setting A subset data retrieved from the Taiwan's

National Health Insurance Research Database.

Participants We identified patients with newly diagnosed diabetes ( $n=1164962)$ during 1999-2013. Participants who had subsequently developed an incident of CRC were placed into the case group, while controls were matched to the cases at a 4:1 ratio by age, gender, date of diabetes diagnosis and the index date of CRC diagnosis.

Methods and outcome measures All variables associated with the risk of CRC entered into a multinomial logistic regression model. The dose-response relationship between various average concentrations of $\mathrm{PM}_{2.5}$ exposure and the incidence of CRC was estimated by logistic regression.

Results The study included a total of 7719 incident CRC cases matched with 30876 controls of random sampling. The mean annual concentration of $\mathrm{PM}_{2.5}$ was $35.3 \mu \mathrm{g} / \mathrm{m}^{3}$. After adjusting for potential confounders, a dose-response relationship was observed between the CRC risks and each interquartile increase of $\mathrm{PM}_{2.5}$ concentration (Q1-Q2:

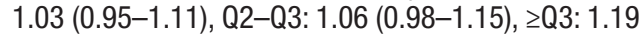
$(1.10-1.28)$ in model 2 . The adjusted ORs $(95 \% \mathrm{Cl})$ of $\mathrm{CRC}$ incidence for each $10 \mu \mathrm{g} / \mathrm{m}^{3}$ increment of $\mathrm{PM}_{25}$ was 1.08 (1.04-1.11). Moreover, a faster growing adapted Diabetes Complications Severity Index (aDCSI) score was noticed in CRC group compared with the controls, which also showed a significant association in our multivariate analysis (adjusted OR=1.28, 95\% $\mathrm{Cl} 1.18$ to 1.38).

Conclusions Long-term exposure to high concentrations of $\mathrm{PM}_{2.5}$ may contribute to an increased incidence of CRC among diabetic populations.

\section{INTRODUCTION}

Air pollution has been identified as the world's single largest environmental health
Strengths and limitations of this study

- This is a nested case-control study on a nationwide diabetic population in Taiwan over a 15-year followup period.

- We conducted two models of conditional logistic regression adjusting for demographic variables alone and with additional clinical variables, respectively.

- The adapted Diabetes Complications Severity Index score, reflecting long-term severity of diabetic complications, was used to assess the cumulative effects of air pollution on glycaemic control.

- Two-pollutant analysis in addition to $\mathrm{PM}_{25}$ alone was employed to examine the joint effects of co-pollutants.

- There may be a misclassification bias because not all participants in the control group had been verified with colonoscopy.

risk by $\mathrm{WHO}$ and is estimated to have caused 4.2 million premature deaths worldwide in 2016 due to ischaemic heart disease and stroke. The International Agency for Research on Cancer classifies ambient particulate pollutants as a group 1 carcinogen related to lung cancer. ${ }^{1}$ Robust evidence from both experimental and epidemiological studies has demonstrated that long-term exposure to air pollution (AP) such as particulate matter $(\mathrm{PM})$, nitrogen dioxide $\left(\mathrm{NO}_{2}\right)$ and ozone $\left(\mathrm{O}_{3}\right)$ is a major risk factor for cardiovascular and cardiopulmonary disease and potentially cancer. ${ }^{2-5}$

Some reports have linked PM with gastrointestinal diseases, including an increased risk of appendicitis, ${ }^{6}$ Crohn's disease in younger individuals ${ }^{7}$ and increased hospitalisation of patients with inflammatory bowel disease, ${ }^{8}$ implying an association between PM exposure and inflammatory diseases of the GI tract. However, there remains a lack of epidemiological evidence connecting exposure to 
ambient air pollutants with the risk of colorectal cancer (CRC). ${ }^{9} 10$

Patients with diabetes are reportedly a vulnerable group susceptible to both oncogenesis ${ }^{11-13}$ and the deleterious effects of AP. ${ }^{14}{ }^{15}$ Documents accrued over the years suggest that diabetes is associated with an increased risk for several malignancies, such as cancer of the breast, ${ }^{16}$ pancreas ${ }^{17}$ and liver ${ }^{18}$ and may also increase the risk of allcause mortality among people with cancer. ${ }^{13}$ In addition, diabetes has been suggested as an independent risk factor of CRC. ${ }^{19}$ A meta-analysis involving 15 studies concluded that individuals with diabetes mellitus (DM) had an $30 \%$ increased risk of CRC. ${ }^{20} \mathrm{DM}$ and CRC share similar risk factors, including physical inactivity, poor diet, excess alcohol consumption, obesity and cigarette smoking. ${ }^{21} 22$

Fine particulate matter is adversely associated with metabolic syndrome-related outcomes such as type 2 diabetes mellitus (T2DM), insulin resistance, hypertension and obesity. ${ }^{23-25}$ Insulin resistance and associated hyperglycaemic, hyperinsulinaemia, oxidative stress and chronic inflammation are the potential mechanisms contributing to the development of diabetes-associated CRC. ${ }^{19} 2226$ Hyperinsulinaemia mediates CRC development through insulin, a growth factor for both normal and cancerous colon cells, and insulin-like growth factor-1 (IGF-1), which may inhibit apoptosis, push forward the cell cycle and promote angiogenesis. ${ }^{27} 28$ Observational studies have demonstrated a linkage between elevated IGF levels and the risks of adenomatous polyps or CRC. ${ }^{29-31}$

In Taiwan, we had an average $\mathrm{PM}_{2.5}$ concentration of $20.5 \mu \mathrm{g} / \mathrm{m}^{3}$ in 2017 , higher than the WHO standard value. $^{32}$ CRC has carried the highest incidence rate among all malignancies since 2007 for both genders combined and has contributed to the third most cancerrelated deaths. ${ }^{31}$ Diabetes, with an estimated prevalence of approximately $11.46 \%$ among adult Taiwanese during 2013-2016, was ranked as the fifth leading cause of all deaths. ${ }^{32}$ Both diseases affect a growing proportion of the general population and bring a heavy burden to the healthcare system in Taiwan.

To explore the role of AP exposure in the risks of diabetes-related malignancies, we conducted the epidemiological study that focus on whether long-term exposure to higher levels of ambient $\mathrm{PM}_{2.5}$ may impair glucose metabolism and therefore influence the incidence of CRC in the diabetic population.

\section{METHOD}

\section{Data source}

The dataset stem from the Taiwanese National Health Insurance Research Database (NHIRD). The NHI programme, implemented on 1 March 1995, provides compulsory universal health insurance, which covers all forms of healthcare services for $98 \%$ of the island's population. We retrieved admission and outpatient records, including information on patient characteristics and up to five discharge diagnoses or three outpatient diagnoses

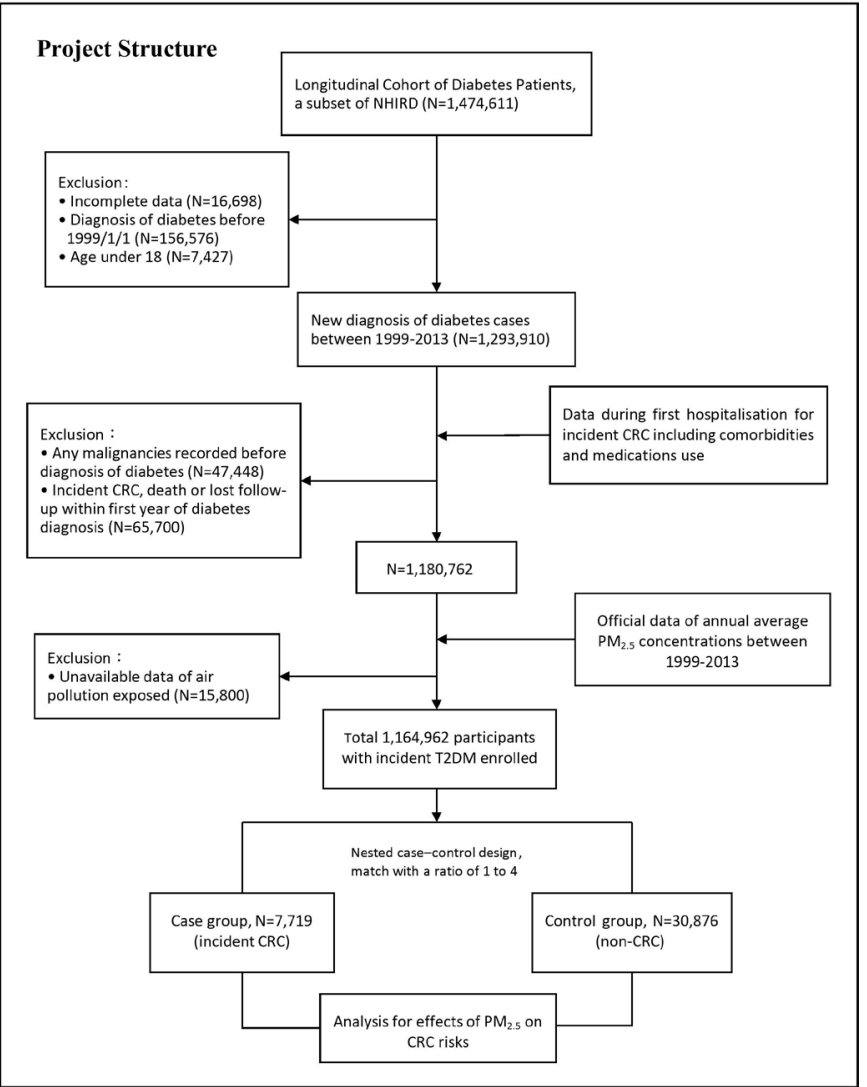

Figure 1 Study architecture and flow chart. CRC, colorectal cancer; NHIRD, National Health Insurance Research Database; T2DM, type 2 diabetes mellitus.

(the International Classification of Diseases, Ninth Revision (ICD-9)). The database had previously been used for epidemiological research and provided information regarding patient prescriptions, diagnoses and hospitalisations. ${ }^{33} 34$ Strict confidentiality guidelines were closely followed in accordance with personal electronic data protection regulations; the National Health Research Institute of Taiwan anonymises and maintains the NHI reimbursement data as files suitable for research.

\section{Identification of study sample}

In the study, we used a subset data from the NHIRD, the Longitudinal Cohort of Diabetes Patients, to identify adult patients with newly diagnosed T2DM (ICD-9 code 250 and A-code A181) during the follow-up period between 1 January 1999 and 31 December 2013. Subject enrolment was restricted to patients with diabetes diagnosis codes from at least one hospital admission or more than three outpatient visits within 1 year. We set up exclusion criteria for the T2DM cohort, including those with incomplete data, unavailable data of AP exposure, age under 18 years, diagnosis of diabetes before 1 January 1999 and previous medical records showing any malignancies before the diagnosis of diabetes (figure 1).

Case-control patient selection from the incident T2DM cohort Within the T2DM cohort, patients who developed incident CRC (ICD-9-CM:153 and 154) during the follow-up 
period were placed into the case group, with the date of CRC diagnosis established as the index date. Only patients who had been admitted with a diagnosis of CRC were enrolled in order to strengthen the validity. In consideration of potential reverse causality, patients who were diagnosed with CRC, dead or lost within the first year of diabetes diagnosis were excluded. Under the setting of a nested case-control study, subjects in the control group were identified through a random sampling at a ratio of 4:1 to the case group after matching for age, gender, date of T2DM diagnosis and the follow-up time or index date of CRC diagnosis.

\section{Exposure assessment for residential $\mathrm{PM}_{2.5}$}

Hourly concentrations of ambient air pollutants including $\mathrm{PM}_{2,5}$, particulate matter with aerodynamic diameters $\leq 10 \mu \mathrm{m}\left(\mathrm{PM}_{10}\right)$, sulfur dioxide $\left(\mathrm{SO}_{2}\right)$, nitric oxide $(\mathrm{NO})$, $\mathrm{NO}_{2}$, carbon monoxide $(\mathrm{CO})$ and $\mathrm{O}_{3}$ were measured at 76 monitoring stations, operated by the Taiwan Environmental Protection Administration (EPA) and located throughout the main Taiwan island. The official data of the annual average $\mathrm{PM}_{2.5}$ concentrations between 1999 and 2013 from the EPA was collected and sorted (see online supplemental file 1). Kriging, a method of spatial interpolation, was used to approximate the actual $\mathrm{PM}_{25}$ level at each participant's residential address using data from the nearest monitoring station. Kriging is a credible method that has been applied in previous studies for estimating ambient PM concentrations at residential addresses. ${ }^{35-38}$

\section{Potential confounders}

All potentially confounding factors related to CRC were identified systematically between 1 January 1999 and the index date of CRC diagnosis. Confounders with sociodemographic characteristics such as age, gender, income and level of urbanisation were taken into consideration. Urbanisation levels in Taiwan are divided into four strata in Taiwanese National Health Research Institute publications; level I indicates the most urbanised communities, while level IV refers to the least urbanised communities.

Associated comorbidities, with a diagnosis validated by at least one hospital admission or more than three outpatient visits within 1 year, included Crohn's disease (ICD-9-CM: 555.0, 555.1, 555.2 and 555.9), ulcerative colitis (ICD-9-CM: 556), constipation (ICD-9-CM: 564.0), colon polyps (ICD-9-CM: 556.4, V12.72 and 211.3), hypertension (ICD-9-CM: 401-405), hyperlipidaemia (ICD-9-CM: 272.0, 272.1 and 272.4), atrial fibrillation (AF) (ICD-9-CM: 427.3 and 427.31), coronary atherosclerosis (ICD-9-CM: 412 and 414.0) and chronic kidney disease (ICD-9-CM: 585). As there were limited data available in the NHIRD regarding individual lifestyles, we used obesity (ICD-9-CM: 278.0), chronic obstructive pulmonary disease (ICD-9-CM: 496, 491.9 and 492.8) and alcohol-related disease (ICD-9-CM: 291, 303.0, $303.9,535.3,571.2$ and 571.3) as surrogate variables for overweight individuals, cigarette smokers and alcohol consumption levels, respectively.

Prescription medications that could potentially confound the association between diabetes and cancer risks were identified, including statins, antihyperlipidaemic drugs, antihypertensive drugs, antihyperglycaemic drugs, aspirin and non-steroidal anti-inflammatory drugs (NSAIDs).

\section{Statistical analysis}

Descriptive statistics regarding demographic and clinical characteristics were analysed to address the baseline distributions of age, gender, urbanisation levels, income, locations in Taiwan, underlying comorbidities, diabetes complications (adapted Diabetes Complications Severity Index (aDCSI) score) and medication use, as compared between the CRC and non-CRC groups. $\chi^{2}$ test and t-test were used to analyse the differences among the categorical and continuous variables, respectively, between the two groups (table 1). The aDCSI score, representing the long-term severity of diabetes, had been validated with clinical outcomes. ${ }^{39}$

Conditional logistic regression was conducted to estimate crude ORs and 95\% CIs to assess the association between various $\mathrm{PM}_{2.5}$ concentrations divided by the interquartile range (IQR) and the risks of CRC incidence. Furthermore, we adjusted for demographic variables, including gender, age, income and urbanisation in model 1 , and additionally adjusted for clinical variables such as comorbidities, drug use and changes in aDCSI score each year in model 2 (table 2).

We then performed the univariate and multivariate logistic regression models to assess the association between the occurrence of CRC and several potential risk factors, including exposure levels of $\mathrm{PM}_{2.5}$, gender, age, income, urbanisation, comorbidities, drug use and change of aDCSI score each year (see online supplemental file 2).

Besides single-pollutant analysis of $\mathrm{PM}_{2.5}$, as a continuous variable for each $10 \mu \mathrm{g} / \mathrm{m}^{3}$ increment in table 3 , we evaluated the joint effects of each co-pollutant combined with $\mathrm{PM}_{2.5}$ in the two-pollutant model to test the consistency of dose-response relationship (table 3). The correlation coefficients of average concentrations between air pollutants were also estimated with the data provided in online supplemental file 3 .

\section{Sensitivity and subgroup analysis}

In addition to the main analysis (model 1), sensitivity analyses were conducted by adding the presence of different comorbidities and drug use (table 4).

All the above analyses were conducted using the SAS V.9.4 software package. All $\mathrm{p}$ values were two tailed, and a $p$ value $<0.05$ was considered significant.

\section{Patient and public involvement}

Patients or public were not involved in the research, including development of the research question, outcome 
Table 1 The demographic and clinical characteristics between patients with and without CRC

\begin{tabular}{|c|c|c|c|}
\hline \multirow[b]{2}{*}{ Characteristic } & CRC $(n=7719)$ & $\begin{array}{l}\text { Non-CRC } \\
(n=30876)\end{array}$ & \multirow[b]{2}{*}{$P$ value } \\
\hline & \multicolumn{2}{|l|}{$N(\%)$} & \\
\hline \multicolumn{4}{|l|}{ Follow-up period* (years) } \\
\hline Mean (SD) & $5.17(2.84)$ & $5.17(2.84)$ & 1 \\
\hline \multicolumn{4}{|l|}{ Gender } \\
\hline Male & $4145(53.70)$ & $16580(53.70)$ & 1 \\
\hline \multicolumn{4}{|l|}{ Age (years) } \\
\hline Mean (SD) & $61.36(10.69)$ & $61.36(10.68)$ & 0.995 \\
\hline$<35$ & $62(0.80)$ & $245(0.79)$ & \\
\hline $35-45$ & $423(5.48)$ & $1683(5.45)$ & \\
\hline $45-55$ & $1722(22.31)$ & $6896(22.33)$ & \\
\hline $55-65$ & 2520 (32.65) & $10108(32.74)$ & \\
\hline $65-75$ & $2225(28.82)$ & 8909 (28.85) & \\
\hline $75-85$ & $716(9.28)$ & $2836(9.19)$ & \\
\hline $85 \leq$ & $51(0.66)$ & $199(0.64)$ & \\
\hline Monthly income (NTD) & & & $<0.004$ \\
\hline 0 & 3228 (41.82) & $12504(40.50)$ & \\
\hline $1-15840$ & $1663(21.54)$ & $6368(20.62)$ & \\
\hline $15841-25000$ & $2196(28.45)$ & $9289(30.08)$ & \\
\hline$\geq 25000$ & $632(8.19)$ & 2715 (8.79) & \\
\hline Urbanisation level & & & 0.430 \\
\hline Low & $699(9.06)$ & $2968(9.61)$ & \\
\hline Moderate & $1445(18.72)$ & $5798(18.78)$ & \\
\hline High & 3439 (44.55) & $13741(44.50)$ & \\
\hline Very high & $2136(27.67)$ & $8369(27.11)$ & \\
\hline Reign of Taiwanף & & & $<0.001$ \\
\hline North & $3134(40.60)$ & $12957(41.96)$ & \\
\hline Central & $1356(17.57)$ & $5836(18.90)$ & \\
\hline South & $2.873(37.22)$ & 10587 (34.29) & \\
\hline East & $356(4.61)$ & $1496(4.85)$ & \\
\hline \multicolumn{4}{|l|}{ Medical diseases } \\
\hline Crohn's disease & $110(1.43)$ & $316(1.02)$ & 0.003 \\
\hline Ulcerative colitis & $36(0.47)$ & $68(0.22)$ & 0.002 \\
\hline Constipation & $1803(23.36)$ & $5440(17.62)$ & $<0.001$ \\
\hline Colon polyps & $752(9.74)$ & $562(1.82)$ & $<0.001$ \\
\hline Hyperlipidaemia & $4230(54.80)$ & $17138(55.51)$ & 0.264 \\
\hline Hypertension & $5419(70.20)$ & 21077 (68.26) & 0.001 \\
\hline Obesity & $122(1.58)$ & $488(1.57)$ & 0.291 \\
\hline Alcohol-related disease & $295(3.82)$ & $804(2.60)$ & $<0.001$ \\
\hline COPD & 1157 (14.99) & $4390(14.22)$ & 0.084 \\
\hline CKD & $503(6.52)$ & $1521(4.93)$ & $<0.001$ \\
\hline CAD & 1427 (18.49) & $5203(16.85)$ & 0.001 \\
\hline AF & $354(4.59)$ & $1132(3.67)$ & $<0.001$ \\
\hline \multicolumn{4}{|l|}{ Medications† } \\
\hline Statin & $3107(40.25)$ & $12548(40.64)$ & 0.534 \\
\hline Antihypertensive drugs $\ddagger$ & 6302 (81.64) & $24391(79.00)$ & $<0.001$ \\
\hline $\begin{array}{l}\text { Antihyperglycaemic } \\
\text { drugs } \neq\end{array}$ & $6088(78.87)$ & $22942(74.30)$ & $<0.001$ \\
\hline
\end{tabular}

Continued
Table 1 Continued

\begin{tabular}{|c|c|c|c|}
\hline \multirow[b]{2}{*}{ Characteristic } & CRC $(n=7719)$ & $\begin{array}{l}\text { Non-CRC } \\
(n=30876)\end{array}$ & \multirow[b]{2}{*}{$P$ value } \\
\hline & \multicolumn{2}{|l|}{$N(\%)$} & \\
\hline $\begin{array}{l}\text { Antihyperlipidaemic } \\
\text { drugs } \neq\end{array}$ & 2024 (26.22) & 8051 (26.08) & 0.794 \\
\hline Aspirin & $3628(47.00)$ & 14501 (46.97) & 0.955 \\
\hline NSAIDs & $6924(89.70)$ & $27616(89.44)$ & 0.507 \\
\hline \multicolumn{4}{|l|}{ aDCSI (score) } \\
\hline $\begin{array}{l}\triangle \mathrm{aDCSI} / \text { follow-time } \\
(\text { mean (SD))§ }\end{array}$ & $0.21(0.34)$ & $0.17(0.31)$ & $<0.001$ \\
\hline Onset (mean (SD)) & $0.87(1.26)$ & $0.89(1.25)$ & 0.316 \\
\hline $\begin{array}{l}\text { End of follow-up (mean } \\
\text { (SD)) }\end{array}$ & $1.88(1.87)$ & $1.73(1.76)$ & $<0.001$ \\
\hline
\end{tabular}

*The follow-time was defined from the start of the follow-up (the diabetes diagnostic date) to the end of the follow-up (the index date of the CRC in the case group to correspond with the control group).

$\dagger$ Drug use is defined as $\geq 28$ cumulative defined daily doses (cDDDs) for taking.

$\ddagger$ Antihypertensive drugs (diuretics, beta-blockers, calcium channel blocker, ACEi and ARB); antihyperglycaemic drugs (insulins, biguanides, sulfonylureas, alpha-Gl, thiazolidinedione and neglitinide); antihyperlipidaemic drugs (non-statin lipid-lowering drug, triglyceridelowering drug).

$\S$ Wilcoxon rank-sum test. §T-test.

INorth (Keelung, Taipei, New Taipei, Taoyuan, Hsinchu and Miaoli); Central (Taichung, Changhua and Nantou); South (Yunlin, Chiayi, Tainan, Kaohsiung and Pingtung); and East (Yilan, Hualien and Taitung).

ACEi, ACE inhibitor; aDCSI, adapted Diabetes Complications Severity Index; $A F$, atrial fibrillation; $C A D$, coronary artery disease; $C K D$, chronic kidney disease; COPD, chronic obstructive pulmonary disease; CRC, colorectal cancer; NSAIDs, non-steroidal anti-inflammatory drugs; NTD, new Taiwan dollars.

measures, study design, recruitment and conduct of the study.

\section{RESULTS}

Among the incident T2DM cohort $(\mathrm{n}=1$ 164962) during the follow-up period between 1999 and 2013, a total of 7719 patients with a recent diagnosis of CRC were identified in the case group. Under the nested case-control setting, a random sampling at a ratio of $4: 1$ to the case group was conducted, which obtained 30876 subjects in the control group after matching by age, gender, date of T2DM diagnosis and follow-up time or index date of CRC diagnosis.

The baseline demographic and clinical characteristics are outlined in table 1. Matching variables including age, gender and follow-up period were distributed evenly between the case and control patients. The mean follow-up period was 5.17 years. Male patients were dominant $(53.70 \%)$ over females. The mean age at diagnosis was 61.36 years, with most cases falling into the age group of 55-65 years. Compared with the control group, the CRC case patients had prevalent comorbidities including Crohn's disease, ulcerative colitis, constipation, colon polyps, hypertension, alcohol-related disease, chronic kidney disease $(\mathrm{CKD})$, coronary artery disease (CAD) and AF. The two groups displayed no differences in their 
Table 2 The crude and adjusted ORs (95\% Cls) of the exposure to $\mathrm{PM}_{25}$ and $\mathrm{CRC}$ in patients with diabetes mellitus

\begin{tabular}{|c|c|c|c|c|c|c|c|}
\hline \multirow[b]{2}{*}{ Variable } & Case & Control & \multirow[b]{2}{*}{ Total no. } & \multirow{2}{*}{$\begin{array}{l}\text { Crude } \\
\text { OR }(95 \% \mathrm{CI})\end{array}$} & \multirow{2}{*}{$\begin{array}{l}\text { Model1* } \\
\text { aOR }(95 \% \mathrm{Cl})\end{array}$} & \multirow{2}{*}{$\begin{array}{l}\text { Model2† } \\
\text { aOR }(95 \% \mathrm{Cl})\end{array}$} & \multirow[b]{2}{*}{$\mathbf{P}$ trend } \\
\hline & No. (\%) & & & & & & \\
\hline$\leq \mathrm{Q} 1$ & $1848(23.94)$ & $7811(25.30)$ & 9659 & - & - & - & $<0.001$ \\
\hline Q2-Q3 & 1908 (24.72) & $7731(25.04)$ & 9639 & 1.05 (0.98 to 1.13$)$ & 1.08 (1.00 to 1.16$)$ & $1.06(0.98$ to 1.15$)$ & \\
\hline$\geq Q 3$ & $2085(27.01)$ & $7564(24.50)$ & 9649 & 1.18 (1.09 to 1.27$)$ & 1.19 (1.10 to 1.29$)$ & 1.19 (1.10 to 1.28$)$ & \\
\hline
\end{tabular}

*Model 1: adjusted for gender, age, income and urbanisation.

†Model 2: in addition to the variants of model 1, it also includes variables such as comorbidities, drug use and change of aDCSI score per year.

aDCSI, adapted Diabetes Complications Severity Index; aOR, adjusted OR; CRC, colorectal cancer; PM ${ }_{2.5}$, particulate matter (diameter less than or equal to $2.5 \mu \mathrm{m})$.

aDCSI scores at onset, but a significantly increasing aDCSI score was observed in the case group $(\triangle \mathrm{aDCSI} /$ time: 0.21 vs $0.17, \mathrm{p}<0.001)$, with a higher aDCSI score at the end of follow-up (1.88 vs 1.73, $\mathrm{p}<0.001)$.

Annual average concentrations of $\mathrm{PM}_{2.5}$ in Taiwan during the period of 1999-2013 are illustrated in figure 2, showing that the mean annual level of $\mathrm{PM}_{2.5}$ was $35.3 \mu \mathrm{g} /$ $\mathrm{m}^{3}$, with the median level at $33.82 \mu \mathrm{g} / \mathrm{m}^{3}$ and an IQR of $11.41 \mu \mathrm{g} / \mathrm{m}^{3}$.

Table 2 lists the crude and adjusted ORs of CRC occurrence after exposure to $\mathrm{PM}_{2.5}$ of various concentrations. When divided into four groups determined by the distribution of $\mathrm{PM}_{2.5}$ concentrations $\left(\leq \mathrm{Q} 1: \leq 29.49 \mu \mathrm{g} / \mathrm{m}^{3}\right.$, Q1Q2: $29.49-33.82 \mu \mathrm{g} / \mathrm{m}^{3}$, Q2-Q3: $33.82-40.90 \mu \mathrm{g} / \mathrm{m}^{3}$ and $\geq$ Q3: $\left.\geq 40.90 \mu \mathrm{g} / \mathrm{m}^{3}\right)$, the crude OR (95\% CI) comparing with the group $\leq \mathrm{Q} 1$ exhibit a dose-response relationship (Q1-Q2: 1.03 (0.96 to 1.11 ), Q2-Q3: 1.05 (0.98 to 1.13) and $\geq Q 3: 1.18$ (1.09 to 1.27)). In both model 1 (adjusting for gender, age, income and urbanisation) and model

\begin{tabular}{|c|c|}
\hline Pollutant & CRC incidence aOR† $(95 \% \mathrm{Cl})$ \\
\hline \multicolumn{2}{|c|}{ Single-pollutant analysis } \\
\hline $\mathrm{PM}_{2.5\left(\operatorname{per} 10 \mu \mathrm{gg} / \mathrm{m}^{3}\right)}$ & 1.08 (1.04 to 1.11$)$ \\
\hline \multicolumn{2}{|c|}{ Two-pollutant analysis } \\
\hline $\mathrm{PM}_{2.5}$ with $\mathrm{NO}$ & 1.07 (1.04 to 1.11$)$ \\
\hline $\mathrm{PM}_{2.5}$ with $\mathrm{NO}_{2}$ & $1.08(1.04$ to 1.11$)$ \\
\hline $\mathrm{PM}_{2.5}$ with $\mathrm{NO}_{\mathrm{x}}$ & 1.08 (1.04 to 1.11$)$ \\
\hline $\mathrm{PM}_{2.5}$ with $\mathrm{CO}$ & 1.08 (1.04 to 1.11$)$ \\
\hline $\mathrm{PM}_{2.5}$ with $\mathrm{SO}_{2}$ & 1.07 (1.03 to 1.12$)$ \\
\hline $\mathrm{PM}_{2.5}$ with $\mathrm{O}_{3}$ & 1.08 (1.05 to 1.12$)$ \\
\hline
\end{tabular}

${ }^{*} \mathrm{OR}$ and $95 \% \mathrm{Cls}$ were calculated on the basis of an increase of $10 \mu \mathrm{g} / \mathrm{m}^{3}$ in exposure to $\mathrm{PM}_{2.5}$.

†Adjusted for gender, age, income, urbanisation, comorbidities, drug use and change of aDCSI score per year.

aDCSI, adapted Diabetes Complications Severity Index; aOR, adjusted OR; CRC, colorectal cancer; $\mathrm{NO}_{2}$, nitrogen dioxide; $\mathrm{PM}_{2.5}$, particulate matter (diameter less than or equal to $2.5 \mu \mathrm{m}$ ).
2 (adjusting for comorbidities, drug use and change of aDCSI score per year, in addition to the variables in model 1), the dose-response relationship of adjusted OR remained significant.

In multivariate analysis (model 2) shown in online supplemental file 2, multiple risk factors for CRC development, other than AP, show significant adjusted ORs (aORs) (95\% CIs). These factors include urbanisation level, age: aOR 1.05 (0.99 to 1.12) per year, Crohn's disease: aOR 1.29 (1.03 to 1.61), ulcerative colitis: aOR 1.90 (1.24 to 2.89 ), constipation: aOR 1.37 (1.29 to 1.46 ), colon polyps: aOR 5.71 (5.08 to 6.41), alcohol-related disease: aOR 1.40 (1.21 to 1.62 ) and change of aDCSI score per year: aOR 1.28 (1.18 to 1.38 ). However, medications including statins, aspirin and NSAIDs among patients with diabetes seem to provide protective effects.

In a single-pollutant analysis, the adjusted ORs $(95 \%$ CIs) of CRC occurrence for each $10 \mu \mathrm{g} / \mathrm{m}^{3}$ increment of $\mathrm{PM}_{2.5}$ level is 1.08 (1.04 to 1.11) in model 2. When combined with other pollutants in a two-pollutant analysis, the results appeared unaffected (table 3).

Sensitivity analysis yielded similar results regarding the dose-response relationship between the concentrations of $\mathrm{PM}_{2.5}$ exposure and the incidence of CRC under various additional covariates in model 1 (table 4).

\section{DISCUSSION}

In this national-based, nested case-control study (ratio 1:4), we examined 7719 patients with incident CRC and 30876 random controls matched by age, gender, index date of CRC diagnosis and date of T2DM diagnosis among 1164962 patients with T2DM during the long follow-up period between 1999-2013. Our study observed the mean annual $\mathrm{PM}_{25}$ of $35.3 \mu \mathrm{g} / \mathrm{m}^{3}$ and the median level of $33.82 \mu \mathrm{g} / \mathrm{m}^{3}$, higher than threefold of the WHO standard, $10 \mu \mathrm{g} / \mathrm{m}^{3}$. When analysed with IQR of $\mathrm{PM}_{2.5}$ concentrations in table 2, a dose-response relationship between the incidents of CRC and ambient concentrations of $\mathrm{PM}_{2.5}$ exposure was observed with the crude OR (95\% CI) of Q1-Q2: 1.03 (0.96 to 1.11), Q2-Q3: 1.05 (0.98 to 1.13), $\geq Q 3: 1.18$ (1.09 to 1.27) compared with the 
Table 4 Sensitivity analyses for the effects of $\mathrm{PM}_{2.5}$ exposure on the first-time $\mathrm{CRC}$ among diabetes mellitus patients in Taiwan with covariates

\begin{tabular}{|c|c|c|c|c|}
\hline & $\leq Q 1$ & Q1-Q2 & Q2-Q3 & $\geq \mathbf{Q} 3$ \\
\hline & OR & OR $(95 \% \mathrm{Cl})$ & OR $(95 \% \mathrm{Cl})$ & OR $(95 \% \mathrm{Cl})$ \\
\hline Main model ${ }^{\star}$ & 1.0 & 1.03 (0.96 to 1.11$)$ & 1.08 (1.00 to 1.16$)$ & 1.19 (1.11 to 1.29$)$ \\
\hline \multicolumn{5}{|l|}{ Main model plus } \\
\hline \multicolumn{5}{|l|}{ Medical diseases } \\
\hline Crohn's disease & 1.0 & $1.03(0.96$ to 1.11$)$ & 1.08 (1.00 to 1.16$)$ & 1.20 (1.11 to 1.29$)$ \\
\hline Ulcerative colitis & 1.0 & 1.03 (0.96 to 1.12$)$ & $1.08(1.00$ to 1.16$)$ & 1.19 (1.11 to 1.29$)$ \\
\hline Constipation & 1.0 & 1.03 (0.96 to 1.12$)$ & 1.07 (0.99 to 1.15$)$ & 1.19 (1.10 to 1.28$)$ \\
\hline Colon polyps & 1.0 & 1.03 (0.96 to 1.11$)$ & 1.07 (0.99 to 1.16$)$ & $1.20(1.11$ to 1.29$)$ \\
\hline Hyperlipidaemia & 1.0 & 1.03 (0.96 to 1.11$)$ & 1.07 (1.00 to 1.16$)$ & 1.19 (1.11 to 1.29$)$ \\
\hline Hypertension & 1.0 & $1.03(0.96$ to 1.11$)$ & 1.08 (1.00 to 1.16$)$ & 1.20 (1.11 to 1.29$)$ \\
\hline Alcohol-related disease & 1.0 & 1.03 (0.96 to 1.12$)$ & 1.08 (1.00 to 1.16$)$ & 1.20 (1.11 to 1.29$)$ \\
\hline Obesity & 1.0 & $1.03(0.96$ to 1.11$)$ & $1.08(1.00$ to 1.16$)$ & 1.19 (1.11 to 1.29$)$ \\
\hline CKD & 1.0 & $1.03(0.96$ to 1.11$)$ & 1.07 (0.99 to 1.16$)$ & 1.19 (1.11 to 1.28$)$ \\
\hline COPD & 1.0 & 1.03 (0.96 to 1.12$)$ & $1.08(1.00$ to 1.16$)$ & 1.20 (1.11 to 1.29$)$ \\
\hline CAD & 1.0 & 1.04 (0.96 to 1.12$)$ & 1.08 (1.00 to 1.16$)$ & 1.20 (1.12 to 1.29$)$ \\
\hline $\mathrm{AF}$ & 1.0 & 1.03 (0.96 to 1.12$)$ & 1.08 (1.00 to 1.16$)$ & $1.20(1.12$ to 1.29$)$ \\
\hline \multicolumn{5}{|l|}{ Medication† } \\
\hline Statin & 1.0 & $1.03(0.96$ to 1.11$)$ & 1.08 (1.00 to 1.16$)$ & 1.19 (1.10 to 1.29$)$ \\
\hline Antihypertensive drugs & 1.0 & $1.03(0.96$ to 1.11$)$ & 1.08 (1.00 to 1.16$)$ & 1.19 (1.11 to 1.29$)$ \\
\hline Diuretic & 1.0 & $1.03(0.96$ to 1.11$)$ & 1.08 (1.00 to 1.16$)$ & 1.20 (1.11 to 1.29$)$ \\
\hline Beta-blocker & 1.0 & $1.03(0.96$ to 1.11$)$ & $1.08(1.00$ to 1.16$)$ & 1.20 (1.11 to 1.29$)$ \\
\hline CCB & 1.0 & $1.03(0.96$ to 1.11$)$ & 1.07 (1.00 to 1.16$)$ & 1.19 (1.11 to 1.28$)$ \\
\hline ACEi & 1.0 & $1.03(0.96$ to 1.11$)$ & 1.08 (1.00 to 1.16$)$ & 1.19 (1.11 to 1.29$)$ \\
\hline ARB & 1.0 & 1.03 (0.96 to 1.12$)$ & $1.08(1.00$ to 1.17$)$ & $1.20(1.12$ to 1.29$)$ \\
\hline Antihyperglycaemic drugs & 1.0 & $1.03(0.96$ to 1.11$)$ & 1.07 (0.99 to 1.15$)$ & $1.18(1.10$ to 1.27$)$ \\
\hline Biguanide & 1.0 & $1.03(0.96$ to 1.11$)$ & $1.08(1.00$ to 1.16$)$ & 1.19 (1.11 to 1.29$)$ \\
\hline Sulfonylurea & 1.0 & $1.03(0.96$ to 1.11$)$ & 1.07 (0.99 to 1.16$)$ & $1.19(1.10$ to 1.29$)$ \\
\hline Alpha-Gl & 1.0 & $1.03(0.96$ to 1.11$)$ & $1.08(1.00$ to 1.16$)$ & $1.20(1.12$ to 1.29$)$ \\
\hline Thiazolidinedione & 1.0 & $1.03(0.96$ to 1.11$)$ & $1.08(1.00$ to 1.16$)$ & 1.20 (1.11 to 1.29$)$ \\
\hline Meglitinide & 1.0 & 1.03 (0.96 to 1.12$)$ & 1.08 (1.00 to 1.16$)$ & 1.20 (1.11 to 1.29$)$ \\
\hline Antihyperlipidaemic drugs & 1.0 & $1.03(0.96$ to 1.11$)$ & $1.08(1.00$ to 1.16$)$ & 1.20 (1.11 to 1.29$)$ \\
\hline Non-statin lipid-lowering drug & 1.0 & $1.03(0.96$ to 1.11$)$ & $1.08(1.00$ to 1.11$)$ & $1.20(1.12$ to 1.29$)$ \\
\hline Triglyceride-lowering drug & 1.0 & $1.03(0.96$ to 1.11$)$ & $1.08(1.00$ to 1.16$)$ & 1.20 (1.11 to 1.29$)$ \\
\hline Aspirin & 1.0 & $1.03(0.96$ to 1.11$)$ & $1.08(1.00$ to 1.16$)$ & 1.20 (1.11 to 1.29$)$ \\
\hline NSAIDs & 1.0 & $1.03(0.96$ to 1.11$)$ & 1.08 (1.00 to 1.16$)$ & 1.19 (1.10 to 1.29$)$ \\
\hline
\end{tabular}

*Models adjusted gender, age, income and urbanisation.

†Drug use is defined as $\geq 28$ cumulative defined daily doses (cDDDs) for taking.

ACEi, ACE inhibitor; AF, atrial fibrillation; Alpha-GI, alpha-glucosidase inhibitor; ARB, angiotensin II receptor blocker; CAD, coronary artery disease; CCB, calcium-channel blocker; CKD, chronic kidney disease; COPD, chronic obstructive pulmonary disease; CRC, colorectal cancer; NSAIDs, non-steroidal anti-inflammatory drugs; $\mathrm{PM}_{2.5}$, particulate matter (diameter less than or equal to $2.5 \mu \mathrm{m}$ ).

group $\leq \mathrm{Q} 1$. After adjusting for potential confounders, the dose-response relationship remained robust in both model 1 and model 2. For each increase of $10 \mu \mathrm{g} / \mathrm{m}^{3}$ in $\mathrm{PM}_{2.5}$ concentration in table 3 , the CRC risk increased by $8 \%$. To the best of our knowledge, our study is the first research that investigates the AP effects on the incidence of CRC in the Taiwanese diabetic population. There is scarce evidence in the literature to make a significant linkage between ambient AP exposure and the risk of CRC in general population, partly due to the long latency required from exposure to oncogenesis in most areas with relatively low concentrations of air pollutants. Our 


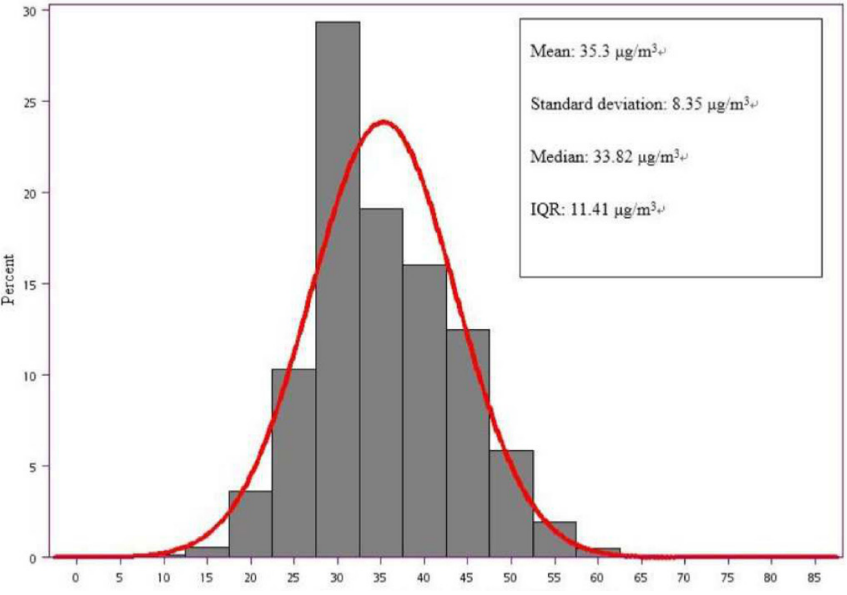

Figure 2 Annual average concentrations of $P M_{2.5}\left(\mu \mathrm{g} / \mathrm{m}^{3}\right)$ in Taiwan during 1999-2013. PM $_{2.5}$, particulate matter (diameter less than or equal to $2.5 \mu \mathrm{m})$.

results with statistical significance may benefit from the advantages of an extended follow-up period, detrimental high-level of AP concentrations and a large diabetic population, a group reportedly susceptible to both malignancies $^{11-13}$ and AP. ${ }^{1415}$

The associations among the three entities, diabetes, AP and CRC, are complicated. Epidemiological studies had revealed the adverse impact of air pollutants on the risks of metabolic syndrome, along with its individual components of fasting blood glucose and hypertriglyceridaemia. ${ }^{40-42}$ Aside from DM incidence, some authors also found that AP may worsen blood glucose control and further aggravate diabetic complications. glycated haemoglobin (HbAlc) was one of the mostly used biomarkers to represent the status of sugar control. For example, a prospective analysis in Europe showed that an increase in HbAlc of $1 \%$ was associated with a $33 \%$ increase in CRC risks in multivariate models. ${ }^{43}$ Another study suggested that $\mathrm{PM}_{2.5}$ and $\mathrm{NO}_{2}$ exposure were related to increased HbAlc levels, with a stronger association in diabetic than non-diabetic American participants, ${ }^{44}$ which is consistent with the reported susceptibility of DM to $\mathrm{AP}^{45}$ In our study, the aDCSI score grew faster in the CRC group compared with non-CRC, which support the association between poor glycaemic control and the CRC risks. Nevertheless, few studies applied the aDCSI score as a measure of glycaemic status. The aDCSI scoring system was designed to quantify the severity of long-term diabetic complications, corresponding to our study objective of investigating the cumulative effects of AP on diabetic populations. $^{46} 47$

Other studies have elucidated the positive associations between AP exposure and insulin resistance. Brook et at ${ }^{48}$ noted that subacute exposure to ambient $\mathrm{PM}_{2.5}$, even at low levels for approximately 5 days, was associated with an increase in the homeostasis model assessment of insulin resistance (HOMA-IR), implying a reduction in insulin sensitivity. In a meta-analysis involving 35 studies, higher levels of fasting glucose, fasting insulin, the HOMA-IR,
HbA1c and C-peptide were all valid predictors for CRC risk. $^{49}$

There are both pathophysiological and molecular processes underlying the association between glucose metabolism and colorectal carcinogenesis. Insulin resistance, with its associated hyperglycaemic and hyperinsulinaemia, may induce colorectal carcinogenesis via inflammatory, oxidative stress and proliferative pathways. ${ }^{50}$ Insulin possesses proproliferative properties and can reduce apoptosis while promoting the growth of CRC cell lines. ${ }^{51}$ Insulin or IGF-I signalling pathways either enhance proliferation, or inhibit apoptosis of colon epithelial cells, leading to carcinogenesis. ${ }^{28} 5253$ In epidemiological studies, higher circulating concentrations of insulin, C-peptide and IGF-I have been demonstrated to increase the risk of CRC. ${ }^{30-59}$ Additionally, a significant increase in the risks of CRC with insulin therapy was also supported by growing evidence. ${ }^{60}$

Experimental studies on diet-induced obese rats have shown subsequent insulin resistance, adiposity and visceral inflammation after $\mathrm{PM}_{2.5}$ exposure. ${ }^{61-64}$ Inhaled small pollutant particles may penetrate the alveoli and enter systemic circulation ${ }^{65}$ leading to low-grade chronic inflammation, as reflected by elevated systemic proinflammatory biomarkers. ${ }^{66-68} \mathrm{PM}_{25}$-exposed mice demonstrated impaired insulin signalling through Akt in their skeletal muscles and adipose tissues. ${ }^{63} \mathrm{PM}_{2.5}$ exposure also triggers inflammation pathways mediated through JNK-AP1, NF-אB and TLR4, while suppressing insulin receptor substrate 1-mediated insulin signalling through Akt and subsequent glycogen synthesis in the liver, which in turn leads to a non-alcoholic steatohepatitis)-like phenotype with impaired hepatic glucose metabolism. ${ }^{69}$

Significant differences in other variables were also observed between the two groups (table 1), including prevalence of comorbidities, deserving more discussions. A notably higher proportion of colon polyps exists among CRC subjects with undesirable sugar control reflected by rapidly raised aDSCI scores, in line with previous reports that poor glycaemic control in diabetes predicts higher tendency to develop colonic adenomatous polyps. ${ }^{70} 71$ Patients with inflammatory bowel disease are reportedly 2-6 times more likely to develop CRC than general population. ${ }^{72}$ Intestinal dysbiosis was well documented to have far-reaching effects on local immunity associated with the pathogenesis of inflammatory bowel disease and CRC and systemic diseases like obesity, diabetes and atherosclerosis. ${ }^{74}$ As for constipation, a delayed stool transit time in patients with diabetes may alter the concentration of bile acids contributing to DNA damage and partly account for the incidence of CRC. ${ }^{75}$ After a literary review, we found meta-analysis and cohort studies sharing the conclusion that patients with CKD have an increased risk of CRC compared with general population, matching with our results. ${ }^{77}$ Alcohol intake has been proposed to be associated with an increased risk of CRC, particularly remarkable with heavy drinking. ${ }^{78} 79$ A metaanalysis of 27 cohort and 34 case-control studies provide 
evidence for a dose-response association between alcohol drinking and CRC risks, with stronger associations for heavy Asian drinkers. ${ }^{80}$ Obesity might interact with alcohol on CRC risks. As reported by a Canadian study, alcohol consumption by people with a body mass index (BMI) $<30$ had an overall CRC OR of 0.8 (95\% CI 0.60 to 1.10), whereas those drinking alcohol with a BMI $>30$, a group with prevailing hyperglycaemia similar to our cohort, had an overall CRC OR of 2.2 (95\% CI 1.20 to 4.00 , p trend $<0.05) .{ }^{81}$ Central obesity and dyslipidaemia, components of metabolic syndrome in addition to hyperglycaemic and hypertension, were also linked with colorectal adenoma in some research. ${ }^{82-84}$ The reason for insignificant differences in coexisting hyperlipidaemia and obesity between our two groups is not well understood, most likely because of the increasing trend in the prescribing of statins and other lipid-lowering drugs for diabetic dyslipidaemia in Taiwan, ${ }^{85} 86$ while the statins had been found to provide a significant chemopreventive effect against colon cancer. ${ }^{8788} \mathrm{AF}$ and CAD also account for greater prevalence in the CRC group, presumably due to shared risk factors.

In two-pollutant analysis while $\mathrm{PM}_{2.5}$ combined with another pollutant except $\mathrm{PM}_{10}$, the results appeared unaffected (table 3). Because only $\mathrm{PM}_{10}$ among other co-pollutants showed high correlation with $\mathrm{PM}_{25}$ by estimating correlation coefficients, it was excluded for twopollutant analysis to avoid multicollinearity. Some papers coincide with our finding of higher correlation between $\mathrm{PM}_{10}$ and $\mathrm{PM}_{2.5}$, as $\mathrm{PM}_{2.5}$ comprise major proportion of $\mathrm{PM}_{10}$ fractions. ${ }^{89}$ Compared with $\mathrm{PM}_{10}$, smaller particles like $\mathrm{PM}_{2.5}$ may permeate lung alveoli and enter into the bloodstream, posing greater harm for systemic cardiovascular effects. ${ }^{90}$ In addition, particulate matter has been shown to be stronger activators of innate immunity in comparison with gaseous pollutants. ${ }^{91} 92$

A number of strengths in our study deserve to be mentioned. First, we analysed a total of 38595 patients with diabetes for a prolonged follow-up period during 1999-2013, based on a nationally representative database, thus allowing for the results to be generalised for a large population. Second, apart from AP, we enrolled multiple variables including demographics, comorbidities, medications and changes in annual aDCSI score for adjusting in multivariate model to assess other confounding effects. Third, we applied the Kriging method, a spatial interpolation model, to obtain township-level estimates of $\mathrm{PM}_{2.5}$ levels that approximate to individual exposure. Fourth, we conducted two-pollutant analysis to evaluate if co-pollutants cause any influence, since other pollutants had reportedly been associated with insulin resistance and T2DM prevalence. ${ }^{429394}$

Nevertheless, several potential limitations should also be acknowledged. First, the NHIRD provides limited personal information regarding smoking habits, alcohol consumption, BMI, family history of T2DM or CRC, diet and physical activity. Thus, we used some comorbidities as surrogates to address those risk factors, such as COPD for smoking, alcohol-related illness for alcohol consumption and obesity for high BMI. Second, similar to most epidemiological studies about AP exposure, residential exposure level may not fully reflect individual cumulative effects. Third, participants in the control group had not all been verified with colonoscopy, so potential odds of misclassification might exist.

\section{CONCLUSION}

Global data revealed that the highest prevalence of cardiometabolic conditions and most cardiovascular events are among developing countries. ${ }^{95}{ }^{96}$ Nonetheless, even low levels of AP have been associated with an excess of cardiometabolic disorders. ${ }^{94} 97$ Our study suggests that long-term exposure to high $\mathrm{PM}_{2.5}$ concentrations may play a promoting role in the growing prevalence of diabetes, as well as an increased incidence of CRC among diabetic populations through the biological mechanisms of systemic inflammation, oxidative stress and elevated insulin resistance. In addition, undesirable control of blood sugar can increase the risk of CRC, as reflected by a raised aDCSI score in this article, warranting an earlier and intensive screening policy for CRC in this group. Considering the widespread prevalence of AP and diabetes, even modest contributions to malignancy risk could cause a substantial effect on public health. As with global urbanisation, ageing and overweight populations with sedentary lifestyles, the harmful influence of ambient AP on the metabolic epidemic might be underestimated and pose an enormous health burden deserving of more attention.

Correction notice The article has been corrected since it is published. The grant numbers have been updated in the Funding section.

Acknowledgements The authors would like to thank Wei-Cheng Chan for statistical analysis.

Contributors Y-TT and W-CH contributed equally to this study. Y-TT and W-CH conceived of the study and supervised all aspects of its implementation. J-WM and T-JL completed the analyses and drafted the content. S-YH and T-CL assisted with the study design and revised the content. T-JL and J-WM assisted with the statistical analysis and revised the content. All authors helped to conceptualise ideas, interpret findings and review drafts of the manuscript.

Funding This work was supported by grants from the China Medical University, Taiwan (grant numbers CMU105-S-48, CMU106-S-34, CMU107-Z-04), and from the Taichung Veterans General Hospital, Taiwan (grant numbers TCVGH-1087202C).

Competing interests None declared.

Patient consent for publication Not required.

Ethics approval This study was approved by the Research Ethics Committee of the China Medical University Hospital in Taiwan.

Provenance and peer review Not commissioned; externally peer reviewed.

Data availability statement All data relevant to the study are included in the article or uploaded as supplementary information. No additional data are available.

Open access This is an open access article distributed in accordance with the Creative Commons Attribution Non Commercial (CC BY-NC 4.0) license, which permits others to distribute, remix, adapt, build upon this work non-commercially, and license their derivative works on different terms, provided the original work is properly cited, appropriate credit is given, any changes made indicated, and the use is non-commercial. See: http://creativecommons.org/licenses/by-nc/4.0/. 


\section{ORCID iDs}

Jen-Wen Ma http://orcid.org/0000-0002-5156-9075

Yu-Tse Tsan http://orcid.org/0000-0001-9148-8811

\section{REFERENCES}

1 IARC Working Group on the Evaluation of Carcinogenic Risks to Humans. Outdoor air pollution. IARC Monogr Eval Carcinog Risks Hum 2016;109:9-444.

2 Brook RD, Newby DE, Rajagopalan S. The global threat of outdoor ambient air pollution to cardiovascular health: time for InterventionThreat of outdoor air pollution to cardiovascular health threat of outdoor air pollution to cardiovascular health. JAMA Cardiology 2017;2:353-4.

3 Brook RD, Rajagopalan S, Pope CA, et al. Particulate matter air pollution and cardiovascular disease: an update to the scientific statement from the American heart association. Circulation 2010;121:2331-78.

4 Hoek G, Krishnan RM, Beelen R, et al. Long-term air pollution exposure and cardio- respiratory mortality: a review. Environ Health 2013;12:43.

5 Lee B-J, Kim B, Lee K. Air pollution exposure and cardiovascular disease. Toxicol Res 2014;30:71-5.

6 Kaplan GG, Dixon E, Panaccione R, et al. Effect of ambient air pollution on the incidence of appendicitis. CMAJ 2009;181:591-7.

7 Kaplan GG, Hubbard J, Korzenik J, et al. The inflammatory bowel diseases and ambient air pollution: a novel association. Am J Gastroenterol 2010;105:2412-9.

8 Ananthakrishnan AN, McGinley EL, Binion DG, et al. Ambient air pollution correlates with hospitalizations for inflammatory bowel disease: an ecologic analysis. Inflamm Bowel Dis 2011;17:1138-45.

9 Datzmann T, Markevych I, Trautmann F, et al. Outdoor air pollution, green space, and cancer incidence in Saxony: a semi-individual cohort study. BMC Public Health 2018:18:715.

10 Lee PN, Thornton AJ, Hamling JS. Epidemiological evidence on environmental tobacco smoke and cancers other than lung or breast. Regul Toxicol Pharmacol 2016;80:134-63.

11 Wojciechowska J, Krajewski W, Bolanowski M, et al. Diabetes and cancer: a review of current knowledge. Exp Clin Endocrinol Diabetes 2016;124:263-75.

12 Sasazuki S, Charvat $\mathrm{H}$, Hara A, et al. Diabetes mellitus and cancer risk: pooled analysis of eight cohort studies in Japan. Cancer Sci 2013;104:1499-507.

13 Barone BB, Yeh H-C, Snyder CF, et al. Long-term all-cause mortality in cancer patients with preexisting diabetes mellitus: a systematic review and meta-analysis. JAMA 2008;300:2754-64.

14 O'Neill MS, Veves A, Zanobetti A, et al. Diabetes enhances vulnerability to particulate air pollution-associated impairment in vascular reactivity and endothelial function. Circulation 2005;111:2913-20.

15 Zanobetti A, Schwartz J. Cardiovascular damage by airborne particles: are diabetics more susceptible? Epidemiology 2002:13:588-92.

16 Heidemann $\mathrm{C}$, Boeing $\mathrm{H}$, Pischon $\mathrm{T}$, et al. Association of a diabetes risk score with risk of myocardial infarction, stroke, specific types of cancer, and mortality: a prospective study in the European prospective investigation into cancer and nutrition (EPIC)-Potsdam cohort. Eur J Epidemiol 2009;24:281-8.

17 Ben Q, Cai Q, Li Z, et al. The relationship between new-onset diabetes mellitus and pancreatic cancer risk: a case-control study. Eur J Cancer 2011:47:248-54

18 El-Serag HB, Hampel H, Javadi F. The association between diabetes and hepatocellular carcinoma: a systematic review of epidemiologic evidence. Clin Gastroenterol Hepatol 2006;4:369-80.

19 Yuhara H, Steinmaus C, Cohen SE, et al. Is diabetes mellitus an independent risk factor for colon cancer and rectal cancer? Am J Gastroenterol 2011;106:1911-21.

20 Larsson SC, Orsini N, Wolk A. Diabetes mellitus and risk of colorecta cancer: a meta-analysis. J Natl Cancer Inst 2005;97:1679-87.

21 Giovannucci E, Michaud D. The role of obesity and related metabolic disturbances in cancers of the colon, prostate, and pancreas. Gastroenterology 2007;132:2208-25.

22 Giovannucci E, Harlan DM, Archer MC, et al. Diabetes and cancer: a consensus report. Diabetes Care 2010;33:1674-85.

23 Brook RD, Sun Z, Brook JR, et al. Extreme air pollution conditions adversely affect blood pressure and insulin resistance: the air pollution and cardiometabolic disease study. Hypertension 2016;67:77-85.
24 Krämer U, Herder C, Sugiri D, et al. Traffic-related air pollution and incident type 2 diabetes: results from the SALIA cohort study. Environ Health Perspect 2010;118:1273-9.

25 Wolf K, Popp A, Schneider A, et al. Association between long-term exposure to air pollution and biomarkers related to insulin resistance, subclinical inflammation, and adipokines. Diabetes 2016;65:3314-26.

26 Sandhu MS, Dunger DB, Giovannucci EL. Insulin, insulin-like growth factor-I (IGF-I), IGF binding proteins, their biologic interactions, and colorectal cancer. J Natl Cancer Inst 2002;94:972-80.

27 Chang CK, Ulrich CM. Hyperinsulinaemia and hyperglycaemia: possible risk factors of colorectal cancer among diabetic patients. Diabetologia 2003;46:595-607.

28 Giovannucci E. Insulin, insulin-like growth factors and colon cancer: a review of the evidence. $J$ Nutr 2001;131:3109S-20.

29 Renehan AG, Zwahlen M, Minder C, et al. Insulin-like growth factor (IGF)-I, IGF binding protein-3, and cancer risk: systematic review and meta-regression analysis. Lancet 2004;363:1346-53.

30 Schoen RE, Weissfeld JL, Kuller LH, et al. Insulin-like growth factor-I and insulin are associated with the presence and advancement of adenomatous polyps. Gastroenterology 2005;129:464-75.

31 Davies M, Gupta S, Goldspink G, et al. The insulin-like growth factor system and colorectal cancer: clinical and experimental evidence. Int $J$ Colorectal Dis 2006;21:201-8.

32 The Environmental Protection Administration. Air pollution statistics: 1-3 concentration of air pollutants. Available: https://www.epa.gov. tw/eng/B19FC7AF2E9ACA66

33 Tsan Y-T, Lee C-H, Wang J-D, et al. Statins and the risk of hepatocellular carcinoma in patients with hepatitis B virus infection. $J$ Clin Oncol 2012;30:623-30

34 Lai M-N, Wang S-M, Chen P-C, et al. Population-based case-control study of Chinese herbal products containing aristolochic acid and urinary tract cancer risk. J Natl Cancer Inst 2010;102:179-86.

35 Huang CC, Wen HJ, Chen PC, et al. Prenatal air pollutant exposure and occurrence of atopic dermatitis. Br J Dermatol 2015;173:981-8.

36 Wang W, Ying Y, Wu Q, et al. A GIS-based spatial correlation analysis for ambient air pollution and AECOPD hospitalizations in Jinan, China. Respir Med 2015;109:372-8.

37 Liao D, Peuquet DJ, Duan Y, et al. GIS approaches for the estimation of residential-level ambient PM concentrations. Environ Health Perspect 2006;114:1374-80.

38 Kim S-Y, Sheppard L, Kim H. Health effects of long-term air pollution: influence of exposure prediction methods. Epidemiology 2009;20:442-50.

39 Chang H-Y, Weiner JP, Richards TM, et al. Validating the adapted diabetes complications severity index in claims data. Am J Manag Care 2012;18:721-6.

40 Wallwork RS, Colicino E, Zhong J, et al. Ambient fine particulate matter, outdoor temperature, and risk of metabolic syndrome. Am J Epidemiol 2017;185:30-9.

41 Pearson JF, Bachireddy C, Shyamprasad S, et al. Association between fine particulate matter and diabetes prevalence in the U.S. Diabetes Care 2010;33:2196-201.

42 Eze IC, Schaffner E, Fischer E, et al. Long-term air pollution exposure and diabetes in a population-based Swiss cohort. Environ Int 2014;70:95-105.

43 Khaw K-T, Wareham N, Bingham S, et al. Preliminary communication: glycated hemoglobin, diabetes, and incident colorectal cancer in men and women: a prospective analysis from the European prospective investigation into cancer-Norfolk study. Cancer Epidemiol Biomarkers Prev 2004;13:915-9.

44 Honda T, Pun VC, Manjourides J, et al. Associations between long-term exposure to air pollution, glycosylated hemoglobin and diabetes. Int J Hyg Environ Health 2017;220:1124-32.

45 O'Neill MS, Veves A, Sarnat JA, et al. Air pollution and inflammation in type 2 diabetes: a mechanism for susceptibility. Occup Environ Med 2007:64:373-9.

46 Hsieh M-H, Sun L-M, Lin C-L, et al. Development of a prediction model for colorectal cancer among patients with type 2 diabetes mellitus using a deep neural network. J Clin Med 2018;7:277.

47 Tseng Y-H, Tsan Y-T, Chan W-C, et al. Use of an $\alpha$-glucosidase inhibitor and the risk of colorectal cancer in patients with diabetes: a nationwide, population-based cohort study. Diabetes Care 2015;38:2068-74.

48 Brook RD, Xu X, Bard RL, et al. Reduced metabolic insulin sensitivity following sub-acute exposures to low levels of ambient fine particulate matter air pollution. Sci Total Environ 2013;448:66-71.

$49 \mathrm{Xu} \mathrm{J}, \mathrm{Ye} \mathrm{Y}, \mathrm{Wu} \mathrm{H}$, et al. Association between markers of glucose metabolism and risk of colorectal cancer. BMJ Open 2016;6:e011430. 
50 Onitilo AA, Engel JM, Glurich I, et al. Diabetes and cancer II: role of diabetes medications and influence of shared risk factors. Cancer Causes Control 2012;23:991-1008.

51 Corpet DE, Jacquinet C, Peiffer G, et al. Insulin injections promote the growth of aberrant crypt foci in the colon of rats. Nutr Cancer 1997;27:316-20.

52 Giovannucci Eet al. Diabetes and cancer. Diabetes Care 2010;33:1674.

53 Sandhu MS, Dunger DB, Giovannucci EL. Insulin, insulin-like growth factor-I (IGF-I), IGF binding proteins, their biologic interactions, and colorectal cancer. CancerSpectrum Knowledge Environment 2002;94:972-80.

$54 \mathrm{Ma}$ J, Pollak MN, Giovannucci E, et al. Prospective study of colorectal cancer risk in men and plasma levels of insulin-like growth factor (IGF)-I and IGF-binding protein-3. J Nat/ Cancer Inst 1999;91:620-5.

55 Kaaks R, Toniolo P, Akhmedkhanov A, et al. Serum C-peptide, insulin-like growth factor (IGF)-I, IGF-binding proteins, and colorectal cancer risk in women. J Natl Cancer Inst 2000;92:1592-600.

$56 \mathrm{Ma}$ J, Giovannucci E, Pollak M, et al. A prospective study of plasma C-peptide and colorectal cancer risk in men. J Natl Cancer Inst 2004;96:546-53.

57 Giovannucci E, Pollak MN, Platz EA, et al. A prospective study of plasma insulin-like growth factor-1 and binding protein-3 and risk of colorectal neoplasia in women. Cancer Epidemiol Biomarkers Prev 2000;9:345-9.

58 Chi F, Wu R, Zeng Y-can, et al. Circulation insulin-like growth factor peptides and colorectal cancer risk: an updated systematic review and meta-analysis. Mol Biol Rep 2013;40:3583-90.

59 Chen L, Li L, Wang Y, et al. Circulating C-peptide level is a predictive factor for colorectal neoplasia: evidence from the meta-analysis of prospective studies. Cancer Causes Control 2013;24:1837-47.

60 Yang Y-X, Hennessy S, Lewis JD. Insulin therapy and colorectal cancer risk among type 2 diabetes mellitus patients. Gastroenterology 2004;127:1044-50.

61 Yan Y-H, Chou CC, Lee C-T, et al. Enhanced insulin resistance in diet-induced obese rats exposed to fine particles by instillation. Inhal Toxicol 2011;23:507-19.

$62 \mathrm{Xu} \mathrm{X,} \mathrm{Yavar} \mathrm{Z,} \mathrm{Verdin} \mathrm{M,} \mathrm{et} \mathrm{al.} \mathrm{Effect} \mathrm{of} \mathrm{early} \mathrm{particulate} \mathrm{air} \mathrm{pollution}$ exposure on obesity in mice: role of p47phox. Arterioscler Thromb Vasc Biol 2010;30:2518-27.

63 Sun Q, Yue P, Deiuliis JA, et al. Ambient air pollution exaggerates adipose inflammation and insulin resistance in a mouse model of diet-induced obesity. Circulation 2009;119:538-46.

$64 \mathrm{Xu} \mathrm{X}$, Liu C, Xu Z, et al. Long-term exposure to ambient fine particulate pollution induces insulin resistance and mitochondrial alteration in adipose tissue. Toxicol Sci 2011;124:88-98.

65 Nemmar A, Hoet PHM, Vanquickenborne B, et al. Passage of inhaled particles into the blood circulation in humans. Circulation 2002;105:411-4.

66 Hoffmann B, Moebus S, Dragano N, et al. Chronic residential exposure to particulate matter air pollution and systemic inflammatory markers. Environ Health Perspect 2009;117:1302-8.

67 Liu Q, Gu X, Deng F, et al. Ambient particulate air pollution and circulating C-reactive protein level: a systematic review and metaanalysis. Int J Hyg Environ Health 2019;222:756-64.

68 Dubowsky SD, Suh H, Schwartz J, et al. Diabetes, obesity, and hypertension may enhance associations between air pollution and markers of systemic inflammation. Environ Health Perspect 2006;114:992-8.

69 Zheng Z, Xu X, Zhang X, et al. Exposure to ambient particulate matter induces a NASH-like phenotype and impairs hepatic glucose metabolism in an animal model. J Hepatol 2013;58:148-54.

70 Huang $\mathrm{X}$, Fan $\mathrm{Y}$, Zhang $\mathrm{H}$, et al. Association between serum $\mathrm{HbA} 1 \mathrm{c}$ levels and adenomatous polyps in patients with the type 2 diabetes mellitus. Minerva Endocrinol 2015;40:163-7.

71 Siddiqui AA, Maddur H, Naik S, et al. The association of elevated $\mathrm{HbA} 1 \mathrm{c}$ on the behavior of adenomatous polyps in patients with typeIl diabetes mellitus. Dig Dis Sci 2008;53:1042-7.

72 Mattar MC, Lough D, Pishvaian MJ, et al. Current management of inflammatory bowel disease and colorectal cancer. Gastrointest Cancer Res 2011;4:53-61.
73 Ekbom A, Helmick C, Zack M, et al. Ulcerative colitis and colorectal cancer. N Engl J Med Overseas Ed 1990;323:1228-33.

74 Kamada N, Seo S-U, Chen GY, et al. Role of the gut microbiota in immunity and inflammatory disease. Nat Rev Immunol 2013;13:321-35.

75 Will JC, Galuska DA, Vinicor F, et al. Colorectal cancer: another complication of diabetes mellitus? Am J Epidemiol 1998;147:816-25.

76 Wu M-Y, Chang T-C, Chao T-Y, et al. Risk of colorectal cancer in chronic kidney disease: a matched cohort study based on administrative data. Ann Surg Oncol 2013;20:3885-91.

77 Komaki Y, Komaki F, Micic D, et al. Risk of colorectal cancer in chronic kidney disease: a systematic review and meta-analysis. $J$ Clin Gastroenterol 2018;52:796-804.

78 Cai S, Li Y, Ding Y, et al. Alcohol drinking and the risk of colorectal cancer death: a meta-analysis. Eur J Cancer Prev 2014;23:532-9.

79 Klarich DS, Brasser SM, Hong MY. Moderate alcohol consumption and colorectal cancer risk. Alcohol Clin Exp Res 2015;39:1280-91.

80 Fedirko V, Tramacere I, Bagnardi V, et al. Alcohol drinking and colorectal cancer risk: an overall and dose-response meta-analysis of published studies. Ann Oncol 2011;22:1958-72.

81 Zhao J, Zhu Y, Wang PP, et al. Interaction between alcohol drinking and obesity in relation to colorectal cancer risk: a case-control study in Newfoundland and Labrador, Canada. BMC Public Health 2012;12:94

82 Liu C-S, Hsu H-S, Li C-I, et al. Central obesity and atherogenic dyslipidemia in metabolic syndrome are associated with increased risk for colorectal adenoma in a Chinese population. BMC Gastroenterol 2010;10:51

83 Giovannucci E. Metabolic syndrome, hyperinsulinemia, and colon cancer: a review. Am J Clin Nutr 2007;86:836S-42.

$84 \mathrm{Kim} \mathrm{BC}$, Shin A, Hong CW, et al. Association of colorectal adenoma with components of metabolic syndrome. Cancer Causes Control 2012;23:727-35

85 Chiang C-W, Chiu H-F, Chen C-Y, et al. Trends in the use of lipidlowering drugs by outpatients with diabetes in Taiwan, 1997-2003. Pharmacoepidemiol Drug Saf 2008;17:62-9.

86 Lin Y-C, Yang C-C, Chen Y-J, et al. Utilization of statins and aspirin among patients with diabetes and hyperlipidemia: Taiwan, 19982006. J Chin Med Assoc 2012;75:567-72.

87 Lee J-W, You N-Y, Kim Y, et al. Statin use and site-specific risk of colorectal cancer in individuals with hypercholesterolemia from the National health insurance Service-National health screening cohort (NHIS-HEALS). Nutr Metab Cardiov Dis 2019;29:701-9.

88 Cheung K-S, Chen L, Chan EW, et al. Statins reduce the progression of non-advanced adenomas to colorectal cancer: a postcolonoscopy study in 187897 patients. Gut 2019;68:1979-85.

89 Das M, Maiti SK, Mukhopadhyay U. Distribution of PM(2.5) and $\mathrm{PM}(10-2.5)$ in $\mathrm{PM}(10)$ fraction in ambient air due to vehicular pollution in Kolkata megacity. Environ Monit Assess 2006;122:111-23.

90 Wang C, Tu Y, Yu Z, et al. PM2.5 and cardiovascular diseases in the elderly: an overview. Int J Environ Res Public Health 2015;12:8187-97.

91 Liu C, Ying Z, Harkema J, et al. Epidemiological and experimental links between air pollution and type 2 diabetes. Toxicol Pathol 2013;41:361-73.

92 Rajagopalan S, Brook RD. Air pollution and type 2 diabetes: mechanistic insights. Diabetes 2012;61:3037-45.

93 Brook RD, Jerrett M, Brook JR, et al. The relationship between diabetes mellitus and traffic-related air pollution. J Occup Environ Med 2008;50:32-8

94 Wang B, Xu D, Jing Z, et al. Effect of long-term exposure to air pollution on type 2 diabetes mellitus risk: a systemic review and meta-analysis of cohort studies. Eur J Endocrinol 2014;171:R173-82.

95 Chow CK, Teo KK, Rangarajan S, et al. Prevalence, awareness, treatment, and control of hypertension in rural and urban communities in high-, middle-, and low-income countries. JAMA 2013;310:959-68.

96 Whiting DR, Guariguata L, Weil C, et al. IDF diabetes atlas: global estimates of the prevalence of diabetes for 2011 and 2030. Diabetes Res Clin Pract 2011;94:311-21.

97 Chen H, Burnett RT, Kwong JC, et al. Spatial association between ambient fine particulate matter and incident hypertension. Circulation 2014;129:562-9. 